\title{
Eficiência reprodutiva de matrizes bovinas de corte submetidas a três diferentes tipos de suplementação mineral ${ }^{1}$
}

\author{
Paulo Vargas Peixoto ${ }^{2}$, Pedro Malafaia ${ }^{2}$, Luciano Vilela Miranda ${ }^{3}$, Camillo C.F. \\ Canella $^{4}$, Camillo C.F. Canella Filho ${ }^{5}$ e Fabrício Vilela Vilas Boas ${ }^{3}$
}

\begin{abstract}
Peixoto P.V., Malafaia P., Miranda L.V., Canella C.F.C., Canella Filho, C.F.C. \& Villas Boas F.V. 2003. [Reproduction performance of beef cattle cows given three different types of mineral supplements.] Eficiência reprodutiva de matrizes bovinas de corte submetidas a três diferentes tipos de suplementação mineral. Pesquisa Veterinária Brasileira 23(3):125-130. Depto Nutrição Animal e Pastagem, Inst. Zootecnia, UFRRJ, Km 47, Seropédica, RJ 23851-970, Brazil. E-mail: pvpeixoto@uol.com.br

The reproduction performance of about 1,200 beef cows, raised on pasture and given three different mineral supplements, was evaluated during 5 years in Cássia county, Minas Gerais, Brazil. The cows were divided into three groups: For one group (A) a commercial mineral mixture was used in 1997 and 1998; for the second group (B) common salt and dicalcium phosphate 1:1 was offered in 1999; and the third group (C) received only common salt during the same year. In 2000 and 2001, all the cows received exclusively common salt. There was no decrease in reproduction efficiency when only common salt was given; on the contrary, the reproduction performance of the inseminated e pregnant cows, that was respectively 92.5 and $78.2 \%(1997)$ and 92.2 and $80.5 \%$ (1998), increased to 94.5 and $85.7 \%$ (2000) and 96.7 and $89.7 \%$ (2001). The decrease of reproduction performance of the cattle in 1999 was probably due to the severe drought during this year. The authors emphasize the importance of a selective mineral supplementation, i.e. to supplement cattle with mineral mixtures including only the elements which the animals can not obtain from the pasture. Theselective mineral supplementation requires the assistance of professionals with training and experience in clinics, pathology and nutrition of ruminants. These professionals should be able to accompany and evaluate the nutritional condition of a herd when a selective mineral mixture is used. Selective mineral supplementation could represent a two or threefold economy of the total cost of conventional supplementation with "complete" mineral mixtures. The authors discuss if the improvement of the reproduction performance of the cattle used in this field experiment was due to a better management of the herd or to possible antagonism between the minerals.
\end{abstract}

INDEX TERMS: Cattle, mineral deficiencies, mineral supplementation, tropical pastures.

\footnotetext{
${ }^{1}$ Recebido em 22 de fevereiro de 2003.

Aceito para publicação em 31 de março de 2003.

${ }^{2}$ Depto Nutrição Animal e Pastagem, Inst. Zootecnia, UFRRJ, Km 47, Seropédica, RJ 23851-970. E-mails: pvpeixoto@uol.com.br, malafaia1@ig.com.br

${ }^{3}$ Médico Veterinário autônomo, Fazenda Palmital, Rua Barão do Rio Branco, 75, Centro, Três Pontas, MG 37190-000.

${ }^{4}$ Médico Veterinário autônomo, Vassouras, RJ 27700-000.

${ }^{5}$ Médico Veterinário, Mestrando em Ciência Animal na Universidade José Rosário Velano, Alfenas, MG.
}

RESUMO.- Em uma fazenda do município de Cássia, Minas Gerais, o desempenho reprodutivo de aproximadamente 1200 matrizes bovinas de corte, criadas a campo, foi avaliado frente a três diferentes tipos de suplementação mineral, durante cinco anos. Enquanto que a mistura A (sal mineral comercial) foi oferecida nos anos de 1997 e 1998, a mistura B (cloreto de sódio $50 \%$ e fosfato bicálcico 50\%) foi disponibilizada, em 1999, para as matrizes mantidas em um dos setores da fazenda e a mistura $C$ (apenas cloreto de sódio), foi oferecida, neste mesmo ano, para os lotes cria- 
dos em outros dois setores. Nos anos de 2000 e 2001, a mistura $C$ foi ofertada a todas matrizes. Não houve queda na eficiência reprodutiva pela suplementação exclusiva com cloreto de sódio, pelo contrário, as percentagens de matrizes inseminadas e matrizes prenhes, que eram, respectivamente, de 92,5 e 78,2 (1997) e 92,2 e 80,5 (1998) alcançaram níveis de 94,5 e 85,7 (2000) e 96,7 e 89,7 (2001). A redução nos índices de matrizes inseminadas e de prenhez verificadas no ano de 1999 foi atribuída à baixa precipitação pluviométrica registrada naquele ano. Os autores ressalvam, porém, que a suplementação seletiva, isto é, aquela baseada na exclusiva administração do (s) mineral (is) que está (ão) faltando em uma determinada fazenda, só deve ser implantada mediante avaliação e acompanhamento clíniconutricional do rebanho, o que exige apoio de profissional com adequados conhecimentos sobre nutrição, deficiências minerais e clínica de ruminantes. Por outro lado, a suplementação seletiva, pode representar uma despesa 2 a 3 vezes menor do que a verificada com a "mineralização" convencional do rebanho. Discute-se se a melhoria dos índices reprodutivos deveu-se à adequação do manejo ou à cessação de possível antagonismo entre os minerais.

TERMOS DE INDEXAÇÃO: Bovinos, deficiências minerais, pastagens tropicais, suplementação mineral.

\section{INTRODUÇÃO}

A ingestão de dietas carentes em minerais ocorre em várias partes do mundo (Underwood 1997). Deficiências minerais severas são detectáveis com relativa facilidade, já que causam perturbações ou sintomas bastante característicos. Estados carenciais mais leves, por cursarem com sinais pouco específicos, como redução na taxa de crescimento, problemas de fertilidade, baixo rendimento de carcaça e menor produção de leite, são tão ou mais importantes, uma vez que passam muitas vezes despercebidos e causam perdas econômicas consideráveis (Tokarnia et al. 2000).

No Brasil, Tokarnia et al. $(1973,1988,1999)$ fizeram três levantamentos detalhados sobre a situação das deficiências minerais, englobando um total de 77 artigos científicos sobre o tema. Por essas revisões, verifica-se que a situação das deficiências minerais é relativamente bem conhecida no país e que existem vastas áreas do território nacional com solos pobres em Sódio $(\mathrm{Na})$ e Fósforo (P) e, em menor escala, em Cobre (Cu) e Cobalto (Co). Existem áreas subdeficientes em Zinco (Zn), muito embora, clinicamente, a paraqueratose de origem dietética não venha sendo registrada (Tokarnia et al. 2000); a paraqueratose hereditária, porém, já foi registrada em Estados da Região Sudeste (Peixoto et al. 1994). Apesar da deficiência de Selênio (Se) já ter sido diagnosticada (Barros et al. 1988), ainda não sabemos sua real importância no Brasil. Com relação ao Iodo (I), há referências antigas sobre ocorrência de bócio em bovinos (Megale 1949, Tokarnia \& Döbereiner 1973); com o advento da iodatação compulsória no cloreto de sódio $(\mathrm{NaCl})$, em princípio, novos casos não deveriam estar ocorrendo, entretanto, há informações de que muitas fábricas de suplementos minerais compram o denominado "sal grosso", o qual não sofre a adição de lodo, apenas é desidratado e moído antes de ser incor- porado ao suplemento mineral. A hipomagnesemia condicionada por excesso de adubação também foi observada no Rio Grande do Sul (Peixoto 1991).

Outro aspecto fundamental a ser considerado é o fato de que as deficiências minerais ocorrem ou estão ligadas a certas áreas geográficas, que naturalmente apresentam diversos tipos de solos, com diferentes concentrações de minerais (Underwood 1997). Assim, existem áreas deficientes, subdeficientes e áreas não-deficientes, muitas vezes próximas umas das outras (Tokarnia et al. 2000).

Nos últimos 30 anos, a suplementação mineral em rebanhos bovinos sofreu considerável incremento, sobretudo em função da massiva propaganda realizada pelas empresas que produzem suplementos minerais. Esse fenômeno foi, por um lado, positivo, pois induziu à conscientização sobre a importância das deficiências minerais como causa de enfermidades e de prejuízos econômicos. Como consequiência, houve um amplo crescimento na suplementação mineral para os rebanhos. Por outro lado, o método mais amplamente utilizado para suplementar e/ou corrigir uma eventual deficiência vem sendo o emprego das assim-denominadas misturas minerais comerciais (MMC), já adquiridas prontas no mercado. Essas MMC, em geral , contém Cálcio (Ca), Fósforo $(\mathrm{P})$, Magnésio $(\mathrm{Mg})$, Enxofre $(\mathrm{S})$, Sódio $(\mathrm{Na})$, Zinco $(\mathrm{Zn})$, Manganês (Mn), Ferro (Fé), Cobre (Cu), Cobalto (Co), Iodo (I) e Selênio (Se) em sua composição. Outras MMC ainda inserem em suas fórmulas Cromo $(\mathrm{Cr})$ e Níquel $(\mathrm{Ni})$, na pressuposição que esses minerais seriam dieteticamente importantes aos bovinos.

De fato, quando saímos a campo, verificamos que, em muitas regiões brasileiras, a suplementação mineral é feita de forma indiscriminada, sem correlação com as necessidades reais dos animais. Além disto, é preciso ter em mente que alimentos de boa qualidade, em muitas situações, podem suprir grande parte ou até mesmo toda necessidade mineral dos animais. Neste último caso, a suplementação mineral torna-se obviamente desnecessária.

Em geral, hoje nos deparamos com as seguintes situações: (1) Parte dos pecuaristas opta pela utilização de uma MMC; (2) Parte compra uma MMC formulada com base no pressuposto de que análises de solo e de forrageiras de sua propriedade possam determinar com exatidão a quantidade de minerais necessária a ser suprida aos animais; (3) Outra parte fornece apenas cloreto de sódio $(\mathrm{NaCl})$ e (4) Uma pequena parcela dos pecuaristas não fornece qualquer suplemento mineral ao rebanho.

Com o objetivo de verificar alternativas na suplementação mineral que não impliquem em perda de produtividade, nesse estudo avaliou-se o desempenho reprodutivo de matrizes bovinas de corte, que inicialmente ingeriam uma MMC e depois, passaram a receber apenas $\mathrm{NaCl}(50 \%)$ e fosfato bicálcico (50\%) e, por fim, exclusivamente $\mathrm{NaCl}$.

\section{MATERIAL E MÉTODOS}

O estudo foi realizado na Fazenda Palmital, município de Cássia, sudeste de Minas Gerais. Trata-se de um estabelecimento com 
aproximadamente 1500 ha destinados à pecuária de corte. A fazenda foi dividida em três grandes setores: Sede, Fazendinha e Fazenda Velha, cada qual com um curral de manejo contendo tronco, brete e balança. Em cada setor, as pastagens possuem cerca de 20 piquetes com aproximadamente 25 a 30 ha.

Com pequenas variações de ano para ano, a fazenda tem, em média, 1200 vacas criadas em regime de pastagens de Brachiaria brizantha, Brachiaria decumbens, Andropogon gayanus, Panicum maximum var. Tanzânia e Mombaça. Todas as matrizes (vacas, primíparas, novilhas de um e de dois anos) são inseminadas com sêmem de touros Nelore, Tabapuã, Red Angus, Santa Gertrudes e Senepol. A fazenda adota uma estação de monta que se inicia em $1^{\circ}$ de dezembro e termina em 31 de março, na qual são realizadas até três inseminações por matriz. Apenas na estação de monta de 2001/ 2002, foi feita uma quarta inseminação.

Durante os anos de 1997-2002, foram realizados os seguintes esquemas de suplementação das matrizes:

- Mistura A (MMC, fornecida a todas matrizes nos anos 1997 e 1998).

- Mistura B (50\% de $\mathrm{NaCl}$ e $50 \%$ de fosfato bicálcico, fornecida em 1999, apenas às matrizes do setor Fazendinha. Neste ano, as matrizes mantidas na Sede e na Fazenda Velha receberam apenas a mistura C).

- Mistura $\mathrm{C}$ (apenas $\mathrm{NaCl}$, fornecida a todas matrizes da Fazenda Palmital nos anos de 2000 e 2001).

Esses suplementos eram sempre disponibilizados nos cochos para minerais, de maneira que nunca faltassem. No período chuvoso, a mistura A continha $80 \mathrm{gP} / \mathrm{kg}$ e, na época seca, $40 \mathrm{gP} / \mathrm{kg}$.

Especificamente para as novilhas, durante a estação seca, era fornecido, ad libitum, um suplemento energético-protéico (proteinado), com aproximadamente $34 \%$ de fubá, $20 \%$ de farelo de soja, $10 \%$ de uréia e $36 \%$ de cloreto de sódio.

Os parâmetros reprodutivos analisados foram o total de matrizes inseminadas (em \% do total de matrizes), o total de matrizes prenhes com uma, duas ou três doses (em \% total de matrizes inseminadas), o total de matrizes prenhes (em \% total de matrizes inseminadas e em \% do total de matrizes) e o número de doses de sêmem por prenhez. Os dados, de cada categoria, foram submetidos à análise de variância e as médias foram comparadas por intermédio do teste " $T$ ", assumindo $5 \%$ de probabilidade.

A precipitação pluviométrica mensal foi quantificada pela Fazenda Experimental de São Sebastião do Paraíso (EPAMIG), que dista cerca de 35 quilômetros da Fazenda Palmital.

\section{RESULTADOS E DISCUSSÃO}

Os principais dados obtidos neste estudo constam nos Quadros 1, 2 e 3 e nas Figuras 1, 2, 3 e 4. Da análise dos dados disponibilizados no Quadro 1, podem ser feitas as seguintes constatações:

Quando o rebanho recebia a mistura A (MMC), a porcentagem de prenhes foi maior do que quando as matrizes passaram a receber as misturas $B$ (setor Fazendinha) e C (setores Sede e Fazenda Velha). Essa redução na porcentagem total de matrizes prênhes na estação de monta de 1999/2000 foi de 17,3 e 19,6 unidades porcentuais (Quadro 3), respectivamente em relação às estações de monta de 1997/1998 e de 1998/ 1999. Por outro lado, quando a porcentagem de prenhez foi avaliada em função do total de matrizes inseminadas, o índice de prenhez pouco se modificou em relação aos dois anos anteriores (Quadro 3).

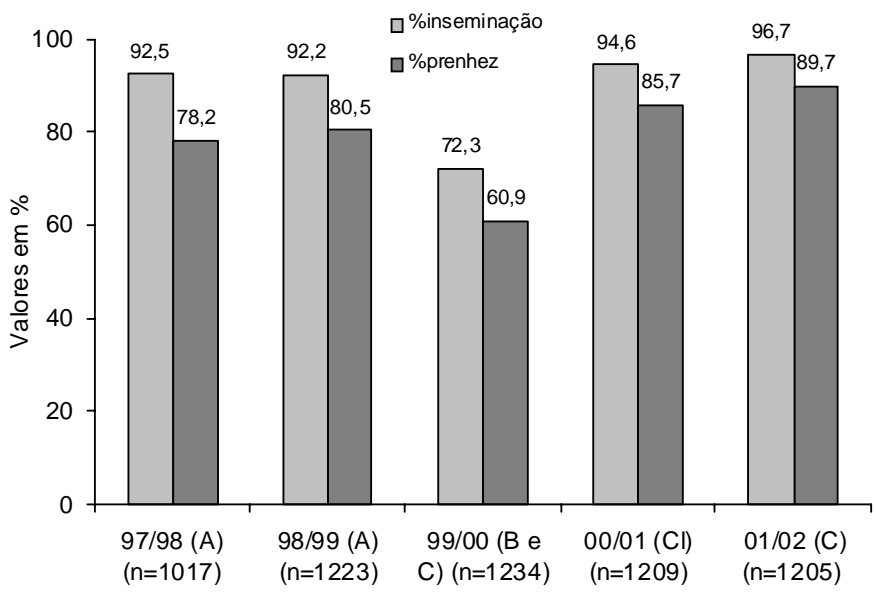

Estação reprodutiva (Mistura mineral) $\left(\mathrm{N}^{0}\right.$. total de vacas )

Fig. 1. Porcentagem de matrizes inseminadas e de matrizes prenhes, verificada na Fazenda Palmital, município de Cássia, Minas Gerais.

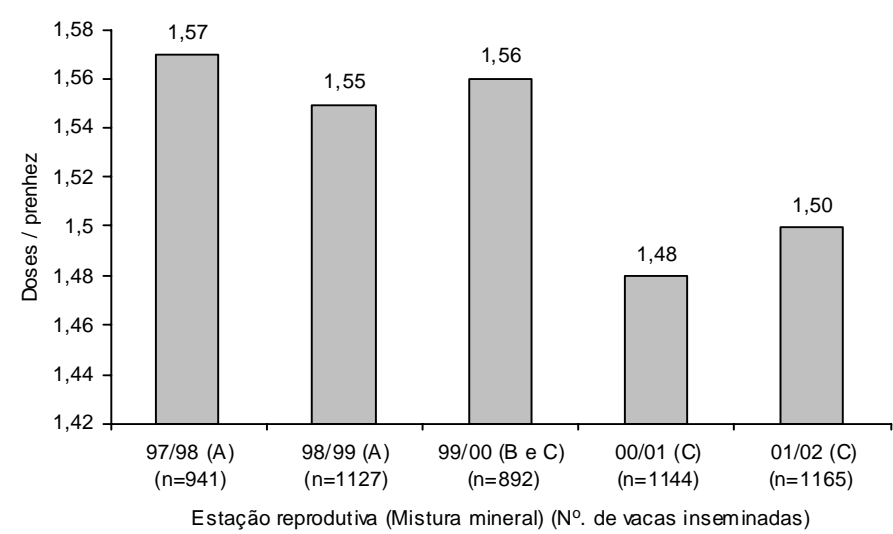

Fig. 2. Relação entre o número de doses de sêmen e prenhez, verificada na Fazenda Palmital, município de Cássia, Minas Gerais.

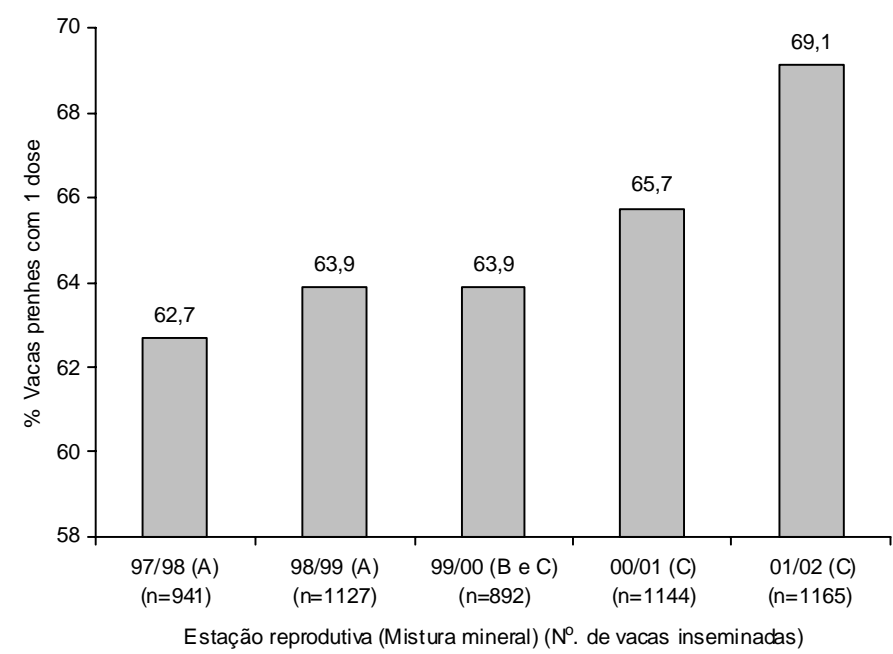

Fig. 3. Porcentagem de matrizes prenhes com uma dose de sêmen, verificada na Fazenda Palmital, município de Cássia, Minas Gerais. 


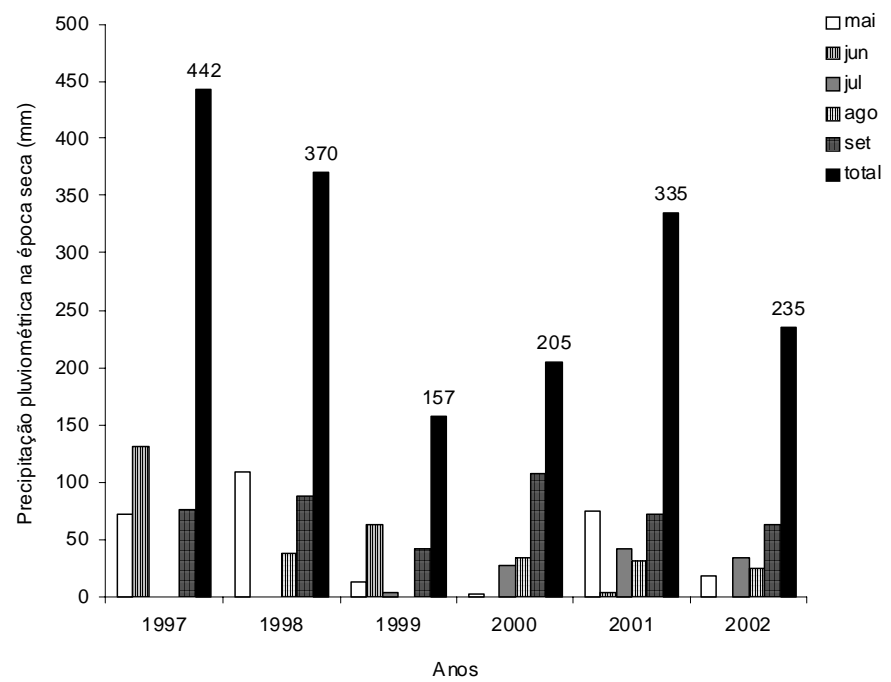

Fig. 4. Precipitação pluviométrica mensal, verificada pela Fazenda Experimental de São Sebastião do Paraíso (Epamig), para o período de seca.
Um exame mais acurado dos dados revela que a marcada redução da porcentagem de matrizes prenhes verificadas na estação de monta de 1999/2000 deve-se, especificamente, à acentuada queda no número de primíparas inseminadas (das 366 primíparas, apenas 160 foram cobertas, Quadro 1). De fato, observa-se que, em relação aos dois anos anteriores, quase não houve variação nos índices de prenhez para vacas, novilhas de um e dois anos na estação de monta de 1999/ 2000 (Quadro 1). Em todos os setores da Fazenda Palmital, independente da utilização das misturas B ou C, os índices de prenhez das primíparas foram sensivelmente reduzidos na estação de monta de 1999/2000 (Quadro 2). Tudo indica que a baixa precipitação pluviométrica (Fig. 4), verificada em 1999 , afetou significativamente os índices reprodutivos das primíparas, que não entraram em cio em função da menor disponibilidade e qualidade das pastagens. Reforçando esta hipótese, verificamos que a distribuição mensal e o volume total de chuvas, acumulado entre maio e outubro deste ano, foi significativamente menor que os índices pluviométricos dos anos anteriores (Fig. 4).

Quadro 1. Parâmetros reprodutivos obtidos em matrizes bovinas de corte na Fazenda Palmital, município de Cássia, Minas Gerais

\begin{tabular}{|c|c|c|c|c|c|c|c|c|c|c|c|c|c|c|c|c|c|c|c|}
\hline \multirow{3}{*}{ Parâmetros } & \multicolumn{19}{|c|}{ Estação de monta } \\
\hline & \multicolumn{3}{|c|}{$\begin{array}{c}\text { 1997/1998 } \\
\text { (Mistura A) }\end{array}$} & \multicolumn{4}{|c|}{$\begin{array}{c}\text { 1998/1999 } \\
\text { (Misttura A) }\end{array}$} & \multicolumn{4}{|c|}{$1999 / 2000^{1}$} & \multicolumn{4}{|c|}{$\begin{array}{c}\text { 2000/2001 } \\
\text { (Mistura C) }\end{array}$} & \multicolumn{4}{|c|}{$\begin{array}{r}\text { 2001/2002 } \\
\text { (Mistura C) }\end{array}$} \\
\hline & Vacas & $\mathrm{P}^{2}$ & $\mathrm{~N} 2 \mathrm{a}^{3}$ & vacas & $P$ & $\mathrm{~N} 1 \mathrm{a}^{4}$ & $\mathrm{~N} 2 \mathrm{a}$ & Vacas & $P$ & N1a & $\mathrm{N} 2 \mathrm{a}$ & Vacas & $P$ & N1a & $\mathrm{N} 2 \mathrm{a}$ & vacas & $P$ & N1a & $\mathrm{N} 2 \mathrm{a}$ \\
\hline Número total & 406 & 226 & 385 & 446 & 271 & 156 & 350 & 560 & 366 & 118 & 190 & 744 & 201 & 89 & 175 & 722 & 189 & 53 & 241 \\
\hline Inseminadas & 383 & 206 & 352 & 435 & 220 & 156 & 316 & 465 & 160 & 118 & 149 & 736 & 152 & 89 & 167 & 710 & 169 & 53 & 233 \\
\hline Cheias & 300 & 175 & 320 & 368 & 199 & 142 & 275 & 398 & 124 & 97 & 133 & 671 & $137^{5}$ & 74 & 154 & 660 & 153 & 53 & 215 \\
\hline Vazias & 83 & 31 & 32 & 67 & 21 & 14 & 41 & 67 & 36 & 21 & 16 & 65 & 15 & 0 & 13 & 50 & 16 & 0 & 18 \\
\hline Não inseminados & 23 & 20 & 33 & 11 & 51 & 0 & 34 & 95 & 206 & 0 & 41 & 8 & 49 & 0 & 8 & 12 & 20 & 0 & 8 \\
\hline Prenhez $\mathrm{c} / 1$ dose & 213 & 135 & 242 & 258 & 165 & 100 & 197 & 295 & 111 & 69 & 95 & 475 & 108 & 49 & 120 & 505 & 112 & 38 & 150 \\
\hline Prenhez c/2 doses & 65 & 37 & 63 & 82 & 29 & 28 & 51 & 86 & 12 & 18 & 31 & 156 & 26 & 21 & 27 & 123 & 34 & 13 & 55 \\
\hline Prenhez c/3 doses & 22 & 3 & 15 & 28 & 5 & 14 & 27 & 17 & 1 & 10 & 7 & 40 & 3 & 4 & 7 & 30 & 7 & 2 & 9 \\
\hline Prenhez c/4 doses & 0 & 0 & 0 & 0 & 0 & 0 & 0 & 0 & 0 & 0 & 0 & 0 & 0 & 0 & 0 & 2 & 0 & 0 & 1 \\
\hline $\begin{array}{l}\text { Doses de sêmen } \\
\text { gastas }\end{array}$ & 658 & 311 & 509 & 707 & 301 & 240 & 503 & 719 & 246 & 198 & 226 & 1102 & 214 & 148 & 234 & 997 & 249 & 70 & 344 \\
\hline $\begin{array}{l}\text { Doses de sêmen/ } \\
\text { prenhez }\end{array}$ & 1,72 & 1,51 & 1,45 & 1,63 & 1,37 & 1,54 & 1,59 & 1,55 & 1,54 & 1,68 & 1,52 & 1,50 & 1,41 & 1,66 & 1,40 & 1,40 & 1,47 & 1,32 & 1,48 \\
\hline Prenhes (\% total) & 73,9 & 77,4 & 83,1 & 82,5 & 73,4 & 91,0 & 78,6 & 71,1 & 33,9 & 82,2 & 70,0 & 90,2 & 68,2 & 83,1 & 88,0 & 91,4 & 81,0 & 100,0 & 89,2 \\
\hline $\begin{array}{l}\text { Prenhes (\% total } \\
\text { inseminadas) }\end{array}$ & 78,3 & 85,0 & 90,9 & 84,6 & 90,5 & 91,0 & 87,0 & 85,6 & 77,5 & 82,2 & 89,3 & 91,2 & 90,1 & 83,1 & 92,2 & 93,0 & 90,5 & 100,0 & 92,3 \\
\hline $\begin{array}{l}\text { Inseminadas } \\
\text { (\% total) }\end{array}$ & 94,3 & 91,2 & 91,4 & 97,5 & 81,2 & 100,0 & 90,3 & 83,0 & 43,7 & 100,0 & 78,4 & 98,9 & 75,6 & 100,0 & 95,4 & 98,3 & 89,4 & 100,0 & 96,7 \\
\hline$\%$ prenhes c/ 1 dose & 55,6 & 65,5 & 68,8 & 59,3 & 75,0 & 64,1 & 62,3 & 63,4 & 69,4 & 58,5 & 63,8 & 64,5 & 71,1 & 55,1 & 71,9 & 71,1 & 66,3 & 71,7 & 64,4 \\
\hline$\%$ prenhes c/2 doses & s 17,0 & 18,0 & 17,9 & 18,9 & 13,2 & 17,9 & 16,1 & 18,5 & 7,5 & 15,3 & 20,8 & 21,2 & 17,1 & 23,6 & 16,2 & 17,3 & 20,1 & 24,5 & 23,6 \\
\hline$\%$ prenhes c/3 doses & s 5,74 & 1,46 & 4,26 & 6,44 & 2,27 & 8,97 & 8,54 & 3,66 & 0,63 & 8,47 & 4,70 & 5,43 & 1,97 & 4,49 & 4,19 & 4,23 & 4,14 & 3,77 & 3,86 \\
\hline
\end{tabular}

${ }^{1}$ Enquanto o lote de matrizes mantidas na Fazendinha recebeu $\mathrm{NaCl}(50 \%)$ e fosfato bicálcico $(50 \%)$, os lotes criados na Sede e na Fazenda Velha receberam apenas NaCl. Os dados reprodutivos (1999/2000) de cada setor da Fazenda Palmital, estão disponibilizados no Quadro 2.

${ }^{2}$ Primíparas.

${ }^{3}$ Novilhas de dois anos.

${ }^{4}$ Novilhas de um ano.

${ }^{5}$ Animais utilizados para o experimento de Lozano (2002). Este lote foi submetido a três esquemas de suplementação, que iniciaram-se dois dias pós-parto e encerraram-se 58 dias depois. Os tratamentos foram:

$1 / 3$ do lote foi suplementado com 225g/dia de MDPS mais $275 \mathrm{~g} /$ dia de caroço de algodão;

$1 / 3$ do lote foi suplementado com $375 \mathrm{~g} /$ dia de MDPS mais $125 \mathrm{~g} /$ dia de soja grão;

$1 / 3$ do lote recebeu uma MMC. 
Quadro 2. Dados reprodutivos da estação de monta 1999/2000, referentes aos três setores da Fazenda Palmital, município de Cássia, Minas Gerais

\begin{tabular}{|c|c|c|c|c|c|c|c|c|c|c|c|c|}
\hline \multirow[t]{2}{*}{ Parâmetros } & \multicolumn{4}{|c|}{$\begin{array}{c}\text { Fazendinha } \\
\text { (Mistura B) }\end{array}$} & \multicolumn{4}{|c|}{$\begin{array}{l}\text { Fazenda Velha } \\
\text { (Mistura C) }\end{array}$} & \multicolumn{4}{|c|}{$\begin{array}{c}\text { Sede } \\
\text { (Mistura C) }\end{array}$} \\
\hline & vacas & $\mathrm{P}^{1}$ & $N 1 a^{2}$ & $\mathrm{~N} 2 \mathrm{a}^{3}$ & vacas & $\mathrm{P}$ & N1a & $\mathrm{N} 2 \mathrm{a}$ & vacas & $\mathrm{P}$ & N1a & $\mathrm{N} 2 \mathrm{a}$ \\
\hline Número total & 184 & 125 & 36 & 26 & 261 & 113 & 31 & 44 & 115 & 128 & 51 & 120 \\
\hline Inseminadas & 128 & 51 & 36 & 25 & 225 & 66 & 31 & 36 & 112 & 43 & 51 & 88 \\
\hline Cheias 107 & 39 & 30 & 24 & 202 & 56 & 27 & 34 & 89 & 29 & 40 & 75 & \\
\hline Vazias $\quad 21$ & 12 & 6 & 1 & 23 & 10 & 4 & 2 & 23 & 14 & 11 & 13 & \\
\hline Não inseminadas & 56 & 74 & 0 & 1 & 36 & 47 & 0 & 8 & 3 & 85 & 0 & 32 \\
\hline Prenhez c/ 1dose & 80 & 34 & 20 & 16 & 146 & 50 & 19 & 28 & 69 & 27 & 30 & 51 \\
\hline Prenhez c/ 2 doses & 20 & 5 & 5 & 8 & 49 & 5 & 4 & 5 & 17 & 2 & 9 & 18 \\
\hline Prenhez c/ 3 doses & 7 & 0 & 5 & 0 & 7 & 1 & 4 & 1 & 3 & 0 & 1 & 6 \\
\hline Prenhez com 4 doses & 0 & 0 & 0 & 0 & 0 & 0 & 0 & 0 & 0 & 0 & 0 & 0 \\
\hline Doses de sêmen gastas & 204 & 80 & 63 & 35 & 334 & 93 & 51 & 47 & 181 & 73 & 84 & 144 \\
\hline Doses de sêmen / prenhez & 1,59 & 1,57 & 1,75 & 1,40 & 1,48 & 1,41 & 1,65 & 1,31 & 1,62 & 1,70 & 1,65 & 1,64 \\
\hline Prenhes (\% total) & 58,15 & 31,20 & 83,33 & 92,31 & 77,39 & 49,56 & 87,10 & 77,27 & 77,39 & 22,66 & 78,43 & 62,50 \\
\hline $\begin{array}{l}\text { Prenhes ( } \% \text { total } \\
\text { inseminadas) }\end{array}$ & 83,59 & 76,47 & 83,33 & 96,00 & 89,78 & 84,85 & 87,10 & 94,44 & 79,46 & 67,44 & 78,43 & 85,23 \\
\hline Inseminadas (\%total ) & 69,57 & 40,80 & 100,0 & 96,15 & 86,21 & 58,41 & 100,0 & 81,82 & 97,39 & 33,59 & 100,00 & 73,33 \\
\hline$\%$ prenhes $\mathrm{c} / 1$ dose & 62,50 & 66,67 & 55,56 & 64,00 & 64,89 & 75,76 & 61,29 & 77,78 & 61,61 & 62,79 & 58,82 & 57,95 \\
\hline$\%$ prenhes c/ 2 doses & 15,63 & 9,80 & 13,89 & 32,00 & 21,78 & 7,58 & 12,90 & 13,89 & 15,18 & 4,65 & 17,65 & 20,45 \\
\hline$\%$ prenhes c/ 3 doses & 5,47 & 0,00 & 13,89 & 0,00 & 3,11 & 1,52 & 12,90 & 2,78 & 2,68 & 0,00 & 1,96 & 6,82 \\
\hline
\end{tabular}

${ }^{1}$ Primíparas.

${ }^{2}$ Novilhas de um ano.

${ }^{3}$ Novilhas de dois anos.

Quadro 3. Médias dos parâmetros reprodutivos obtidos em matrizes bovinas de corte na Fazenda Palmital, município de Cássia, Minas Gerais

\begin{tabular}{lccccc}
\hline \multirow{2}{*}{ Parâmetros } & \multicolumn{5}{c}{ Estação de monta } \\
\cline { 2 - 6 } & $1997 / 98$ & $1998 / 99$ & $1999 / 00$ & $2000 / 01$ & $2001 / 02$ \\
\hline Mistura utilizada & $\mathrm{A}$ & $\mathrm{A}$ & $\mathrm{B} \mathrm{e} \mathrm{C}$ & $\mathrm{C}$ & $\mathrm{C}$ \\
Total de matrizes & 1017 & 1223 & 1234 & 1209 & 1205 \\
Inseminadas & 941 & 1127 & 892 & 1144 & 1165 \\
Cheias & 795 & 984 & 752 & 1036 & 1081 \\
Vazias & 146 & 143 & 140 & 93 & 84 \\
Não inseminadas & 76 & 96 & 342 & 65 & 40 \\
Prenhes c/ 1dose & 590 & 720 & 570 & 752 & 805 \\
Prenhes c/ 2 doses & 165 & 190 & $147^{2}$ & 230 & 225 \\
Prenhes c/ 3 doses & 40 & 74 & 35 & 54 & 48 \\
Prenhes com 4 doses & 0 & 0 & 0 & 0 & 3 \\
Doses de sêmen gastas & 1478 & 1751 & 1389 & 1698 & 1747 \\
Doses de sêmen / prenhes & $1,57^{\text {a* }}$ & $1,55^{\mathrm{a}}$ & $1,56^{\mathrm{a}}$ & $1,48^{\mathrm{a}}$ & $1,50^{\mathrm{a}}$ \\
Matrizes prenhes (\% total) & $78,2^{\mathrm{b}}$ & $80,5^{\mathrm{b}}$ & $60,9^{\mathrm{c}}$ & $85,6^{\mathrm{a}}$ & $89,7^{\mathrm{a}}$ \\
Matrizes prenhes & $84,4^{\mathrm{b}}$ & $87,3^{\text {ab }}$ & $84,3^{\mathrm{b}}$ & $90,6^{\text {ab }}$ & $92,8^{\mathrm{a}}$ \\
(\% total inseminadas) & & & & & \\
Matrizes inseminadas (\% total) & $92,5^{\mathrm{a}}$ & $92,1^{\mathrm{a}}$ & $72,2^{\mathrm{b}}$ & $94,6^{\mathrm{a}}$ & $96,7^{\mathrm{a}}$ \\
\% matrizes prenhes c/ 1 dose & $62,7^{\mathrm{a}}$ & $63,8^{\mathrm{a}}$ & $63,9^{\mathrm{a}}$ & $65,7^{\mathrm{a}}$ & $69,1^{\mathrm{a}}$ \\
\% matrizes prenhes c/ 2 doses & $17,5^{\mathrm{a}}$ & $16,8^{\mathrm{a}}$ & $16,4^{\mathrm{a}}$ & $20,1^{\mathrm{a}}$ & $19,3^{\mathrm{a}}$ \\
\% matrizes prenhes c/ 3 doses & $4,25^{\mathrm{a}}$ & $6,57^{\mathrm{a}}$ & $3,92^{\mathrm{a}}$ & $4,72^{\mathrm{a}}$ & $4,12^{\mathrm{a}}$
\end{tabular}

"Médias em mesma linha, seguidas de letras iguais, não diferem entre si pelo teste $\mathrm{t}$.

O fornecimento da mistura $\mathrm{C}$ (somente $\mathrm{NaCl}$ ) para todas as matrizes da Fazenda Palmital, coincidiu com a melhoria dos índices reprodutivos em 2000/2001 e em 2001/2002 (Quadros 1 e 2). As hipóteses que podem ser formuladas para explicar esse aumento, aparentemente paradoxal, são a melhora geral do manejo do rebanho, a qualificação da mão-deobra que atuava na área da reprodução e a anulação de possí- veis antagonismos entre os minerais. 0 proprietário informou que o manejo geral não foi alterado, mas que a qualificação dos funcionários vem sendo constantemente melhorada, o que em parte, pode ser comprovada pela crescente elevação nos índices de matrizes inseminadas com uma única dose de sêmen (Fig. 3). Quanto à alimentação do rebanho, nada foi alterado, uma vez que o mesmo é criado exclusivamente a pasto.

A cessação de possíveis antagonismos entre os minerais da dieta é difícil de ser comprovada, pois não foram realizados estudos sobre balanço mineral, nem análises químicas de tecidos e fluidos dos animais.

\section{DISCUSSÃO E CONCLUSÕES}

A interpretação do conjunto de dados obtidos no presente estudo indica que o fornecimento exclusivo de $\mathrm{NaCl}$ resultou em índices reprodutivos totalmente satisfatórios para as condições de manejo e de alimentação utilizados na Fazenda Palmital, evidenciando que, nesta situação, as pastagens supriram inteiramente as exigências dos outros minerais para os animais. É oportuno, porém, salientar que esses resultados se referem, em específico, às condições dessa fazenda. Sabe-se que as deficiências minerais são muito variáveis dentro de uma mesma região, de forma que quaisquer modificações que envolvam a suplementação mineral do rebanho devem ser introduzidas cautelosamente, caso a caso, isto é, analisando-se individualmente cada propriedade.

Ao nosso ver, o caminho mais lógico a ser seguido, quando se quer promover modificações na "mineralização" do rebanho, é o que chamamos de suplementação seletiva; isto é, administrar-se apenas o mineral (ais) que está (ão) em nível(is) 
insuficiente(s) na dieta total. A questão central, neste caso, é o reconhecimento de qual (is) mineral (ais) está (ão) deficiente (s) na dieta. Essa suplementação seletiva só pode ser implantada com avaliação e acompanhamento clínico/nutricional do rebanho, o que exige, de parte do profissional, adequados conhecimentos sobre nutrição, deficiências minerais e clínica de ruminantes.

Não se advoga, em função dos dados observados neste estudo, o abandono imediato de programas de suplementação mineral já existentes; pelo contrário, nossa sugestão é que, para tal, seja realizado um ensaio de reversão, alicerçado em um protocolo experimental onde um grupo de animais irá receber a MMC e outro grupo, uma mistura mineral proposta com base no exame clínico-epidemiológico do rebanho, bem como no manejo nutricional dos animais.

Não há dúvidas que ao administrarmos apenas aquele(s) elemento(s) que está (ão) deficitário(s), os custos com a suplementação serão bem menores do que aqueles verificados para as misturas minerais que são adquiridas prontas (MMC). Estas misturas "completas" são mais caras por razões comerciais e também por terem vários elementos minerais tidos, equivocadamente, como imprescindíveis aos animais. Além disto, a suplementação seletiva, por implicar na presença de um menor número de elementos no suplemento, reduz a probabilidade de antagonismos entre eles.

Uma avaliação comparativa entre as vantagens e desvantagens das suplementações convencional e seletiva deve ser objeto de estudos, que levem em consideração os aspectos econômicos, o manejo, bem como a eficiência na profilaxia e tratamento de estados deficitários relativos à insuficiência de minerais na dieta; o resultado dessa comparação, porém, diz respeito apenas à propriedade em questão.

Através de levantamentos dos preços de suplementos minerais comerciais em diversos Estados do país, verificamos que a suplementação seletiva tem um custo, em média, 2 até 3 vezes menor que aquele da suplementação convencional (Peixoto \& Malafaia 2003).

Ainda no que se refere ao lado econômico, temos observado que esses custos com suplementação convencional podem ser ainda maiores em função do elevado consumo diário (70-120 g/dia) de algumas MMC, muitas vezes formuladas com baixos teores de $\mathrm{NaCl}$. É fato conhecido que o $\mathrm{NaCl}$, em uma mistura mineral, atua como regulador ("freio") no consumo voluntário do suplemento mineral (Underwood 1997). Em um levantamento feito a partir de informações do teor de $\mathrm{Na}(\mathrm{g} /$ $\mathrm{kg}$ ) em $15 \mathrm{MMC}$, foram observados valores médios de 38,2\% de $\mathrm{NaCl}$, com valor máximo de 65 e mínimo de $25 \%$ (Malafaia \& Peixoto 2003). Esses níveis médios podem proporcionar consumos diários maiores do que $100 \mathrm{~g} / \mathrm{dia}$, muito distante da média de $30 \mathrm{~g} / \mathrm{cab} . /$ dia, relatada por Underwood (1997) e Tokarnia et al. (2000).
Em relação ao manejo, enquanto a utilização das misturas comerciais é mais prática, a adoção da suplementação seletiva envolve a compra dos ingredientes e a formulação da mistura. Para formular um suplemento faz-se necessário conhecer o requerimento do(s) mineral (is) e o(s) teor (es) do (s) elemento (s) no(s) ingrediente (s). Essas etapas envolvem mais tempo e trabalho. Também é importante atentar para o cuidado que se deve ter na preparação da mistura para eliminar a possibilidade de intoxicações, o que pode ser evitado por meio de uma boa homogeneização. A adequada uniformização pode ser conseguida quando se dilui crescentemente as fontes de microminerais no $\mathrm{NaCl}$.

No que diz respeito à eficiência dos suplementos minerais, sabe-se que, em áreas onde a carência de um mineral específico é muito marcada, muitas MMC podem não suprir as necessidades dos animais, uma vez que são formuladas para situações gerais. Já a suplementação seletiva, sempre implementada em situações específicas, permite que os ajustes em sua composição possam resultar em maior eficiência na profilaxia e na resolução dos problemas com deficiências minerais.

\section{REFERÊNCIAS}

Barros C.L., Barros S.S., Santos M.N. \& Metzdorf L.L. 1988. Miopatia nutricional em bovinos no Rio Grande do Sul. Pesq. Vet. Bras. 8(3/4):51-55.

Lozano D.M. 2002. Desempenho reprodutivo de vacas primíparas RedAngusxZebu suplementadas no pós parto. Dissertação de Mestrado, Univ. Fed. Lavras, Minas Gerais. 59p.

Malafaia P. \& Peixoto P.V. 2003. Dados não publicados (Univ. Fed. Rural do Rio de Janeiro).

Megale F. 1949. Contribuição ao estudo do bócio congênito nos bezerros, no Estado de Minas Gerais. Arquivos da Escola de Veterinária, Belo Horizonte, 2:143-150.

Peixoto P.V. 1991. Dados não publicados (Univ. Fed. Rural do Rio de Janeiro). Peixoto P.V. \& Malafaia P. 2003. Dados não publicados (Univ. Fed. Rural do Rio de Janeiro).

Peixoto P.V., Moraes S.S. \& Lemos R.A. 1994. Ocorrência da paraqueratose hereditária (Linhagem letal A-46) no Brasil. Pesq. Vet. Bras. 14(2/3):7984.

Tokarnia C.H. \& Döbereiner J. 1973. Diseases caused by mineral deficiencies in cattle raised under range conditions in Brazil, a review. Pesq. Agropec. Bras. 8(Supl.):1-6.

Tokarnia C.H., Döbereiner J. \& Moraes S.S. 1988. Situação atual e perspectivas da investigação sobre nutrição mineral em bovinos no Brasil. Pesq. Vet. Bras. 8(1/2):1-16.

Tokarnia C.H., Döbereiner J. \& Peixoto P.V. 1999. Deficiências e desequilíbrios minerais em bovinos e ovinos - revisão dos estudos realizados no Brasil de 1987 a 1998. Pesq. Vet. Bras. 19(2):47-62.

Tokarnia C.H., Döbereiner J., Peixoto P.V. \& Canella C.F.C. 2000. Deficiências minerais em animais de fazenda, principalmente bovinos. Pesq. Vet. Bras. 20(3):127-138

Underwood E.J. \& Suttle N.F. 1997. The Mineral Nutrition of Livestock. CABI Publishing, London. 609p. 